\title{
Method of preserving animal substances
}

\section{Gannal}

To cite this article: M. Gannal (1844) Method of preserving animal substances, Philosophical Magazine Series 3, 24:162, 545-546, DOI: 10.1080/14786444408644919

To link to this article: http://dx.doi.org/10.1080/14786444408644919

册 Published online: 30 Apr 2009.

Submit your article to this journal 준

Џll Article views: 2

Q View related articles $₫$ 
The advantages which this process possesses over every other must be, I think, apparent. The papers are prepared in the most simple manner, and may be kept ready by the tourist until required for use. They require no preparation previously to their being placed in the camera, and they can be preserved until a convenient opportunity offers for bringing out the picture, which is done in the most simple manner, with a material which can be anywhere procured.

Anxious to give the public the advantage of this process during the beautiful weather of the present season, I have not waited to perfect the manipulatory details which are necessary for the production of portraits. It is sufficient, however, to say, that experiment has satisfied me of its applicability for this purpose.

Prismatic examination has proved that the rays effecting this chemical change are those which I have elsewhere shown to be perfectly independent of solar light or heat. I therefore propose to distinguish this process by a name which has a general rather than a particular application. Regarding all photographic phænomena as due to the principle Energia, I would nevertheless wish to distinguish this very interesting process as the Energiatype.

I enclose you a few specimens of the results already obtained. The exceeding sensibility of the Energiatype is best shown by an attempt to copy engravings or leaves by it. The three specimens I enclose were produced by an exposure of considerably less than one second.-Athencum.

In a subsequent number of the 'Athenæum,' Mr. Hunt has given the following additional directions :-

Experience has suggested to me the advantage of adding to the solution of succinic acid and gum, as previously given, 5 grains of common salt. This preserves the lights very clear, and indeed improves the sensibility of the paper.

When the solution of the sulphate of iron is laid over the paper, it is requisite to keep disturbing it, by rapidly but lightly brushing it up; otherwise numerous little black specks form, which destroy the photograph. If, as sometimes happens, the surface of the picture blackens all over, it must not be concluded that the drawing is destroyed. The whole of this superficial blackness may be removed by immediately washing with a wet sponge. If the lights become in any way discoloured, a little exceedingly diluted hydrochloric (muriatic) acid will restore them to their proper degree of whitenesss; but care must be taken that the acid is speedily washed off; or the shadows will suffer.

When, from the shortness of the exposure, the image developes itself slowly or imperfectly, a slight degree of warmth brings out the picture with rapidity and force. Holding the paper a short distance from the fire is the best mode of operating.

METHOD OF PRESERVING ANIMAL SUbSTANCES. BY M. GaNNAL.

From the observations made by M. Gannal, and reported to the Académie des Sciences at a recent sitting, it appears that arsenic Phil. Mag. S. 3. No. 162. Suppl. Vol. 24. 
does not permanently preserve animal substances, although it prevents, for the moment, a putrid fermentation.

He alludes to his former communication, explaining how the salts of alumina act on the gelatine and preserve the animal matter from putrid fermentation by the combination of the two substances. The gelatine is thus rendered incapable of putrefaction; but the other evil, viz. the destruction by insects, is not avoided. For the latter object he proposes the following preparation:-

1 kilogramme of sulphate of alum -1 kilog. $=2 \frac{1}{4} \mathrm{lbs}$, avoird.;

100 grammes of nux vomica in powder- 100 grammes $=3 \frac{1}{2}$ oz. av.;

And 3 litres of water-3 litres $=5 \frac{1}{4}$ imperial pints.

The above to be boiled down to $2 \frac{1}{2}$ litres, and then allowed to cool : the clear liquid is to be drawn off and serves for injection. The residue is employed in the following manner. With four tablespoonsful of this residue mix the yolk of one egg; let this paste be prepared as wanted. It is to be used for covering the interior of the skin, and particularly the fleshy parts which may have been left in skinning the animal. The yolk of egg serves to preserve the suppleness of the skin, tanned by the salts of alum.

In order to preserve the feathers of birds he proposes three modes :-

1. The employment of nux vomica in powder.

2. An alcoholic tincture of 100 grammes of nux vomica, macerated in 1 litre of alcohol.

3. An alcoholic solution of 2 grammes of strychnine in 1 litre of alcohol.

Whatever mode may have been used for preserving the animal, the ravages of insects may be instantly arrested by covering with a soft brush the whole of the skin, either with the tincture or solution above described, as may be found best adapted.

If the feathers of birds are of delicate colour, the solution of strychnine should be employed; and for those very delicate birds, where soaking in either of the preparations is not possible, the nux vomica must be used in powder, taking care to insert it well in the napes of feathers. In all cases the inside of the skin may be rubbed with the paste.

In conclusion he states that from his experience he feels assured-

That no arsenical preparation can ensure the preservation of animal substances;

That they are destroyed by exposure to the air for a period exceeding three years ;

That those substances enclosed in hermetically sealed cases are destroyed even in one year;

That the soluble salts of alumina are quite effective in arresting putrid iermentation; and

That the employment of the preparation of nux vomica, as described, perfectly preserves animal substances from the attacks of insects. - From the Proceedings of the Zool. Soc. Nov. 28th, 1843. 